\section{An Efficient Method for Rooting and Acclimation of Micropropagated Apple Cultivars}

\author{
Jyothi Prakash Bolar' ${ }^{1}$ John L. Norelli, and Herb S. Aldwinckle \\ Department of Plant Pathology, Cornell University, New York State Agricultural \\ Experiment Station, Geneva, NY 14456

\section{Viola Hanke} \\ Institute for Fruit Breeding, Federal Center For Breeding Research in Cultivated \\ Plants, Pillnitzer Platz 2, 01326 Dresden, Germany
}

\section{Additional index words. Malus $\times$ domestica, tissue culture, Trichoderma, in vitro, root induction, root elongation}

\begin{abstract}
To root tissue-cultured apple cultivars, shoots from proliferating cultures were first transferred to root induction medium with IBA for 1 week in the dark. Shoots were later transferred to the same medium without IBA and incubated under light for elongation of the roots. Rooted shoots were then transferred to Jiffy-7s supplemented with biological plant protectant and fertilizer, and incubated in plastic humidity trays. After 2 to 3 weeks, plants were transferred to pots and covered with plastic bags to facilitate acclimation. This technique has resulted in $70 \%$ to $100 \%$ of shoots selected in vitro producing vigorously growing, healthy plants in the greenhouse. Chemical name used: indolebutyric acid (IBA).
\end{abstract}

The efficient and reliable production of vigorously growing plants in soil from in vitro plant material is an important step in the evaluation of transgenic apple (Malus $\times$ domestica Borkh.) lines. Research on the factors involved in the development of effective rooting techniques has yielded variable success (Skirvin and Sriskandarajah, 1993; Zimmerman, 1984; Zimmerman and Fordham, 1985).Zimmerman (1984) recommended a combination of treatments for in vitro rooting, which included placing the shoots on rooting medium in the dark for the first week at $30^{\circ} \mathrm{C}$, then moving them in the same medium to a regime of $16 \mathrm{~h}$ light $/ 8 \mathrm{~h}$ dark at $25^{\circ} \mathrm{C}$. Rooting percentages up to $100 \%$ were obtained in vitro but the success rate for acclimation and establishment of the plants in the greenhouse was not reported. Zimmerman and Fordham (1985) reported interaction among light, temperature, type of auxin, salt, and phloroglucinol on root initiation in liquid medium, and later root elongation in preformed peat plugs. Acclimation of these rooted plants and their establishment in the greenhouse are stages where plant loss often occurs, and success rates at this critical

Received for publication 23 Mar. 1998. Accepted for publication 22 June 1998. This research was funded in part by a grant from the Cornell Center for Advanced Technology in Biotechnology, which is sponsored by the New York State Science and Technology Foundation and industrial partners. The cost of publishing this paper was defrayed in part by the payment of page charges. Under postal regulations, this paper therefore must be hereby marked advertisement solely to indicate this fact.

'Graduate Research Assistant. e-mail: jpb10 @ cornell.edu step have not been reported. Here we report details of a method that has a high success rate ( $70 \%$ to $100 \%$ ) for rooting and acclimation of in vitro-derived apple cultivars.
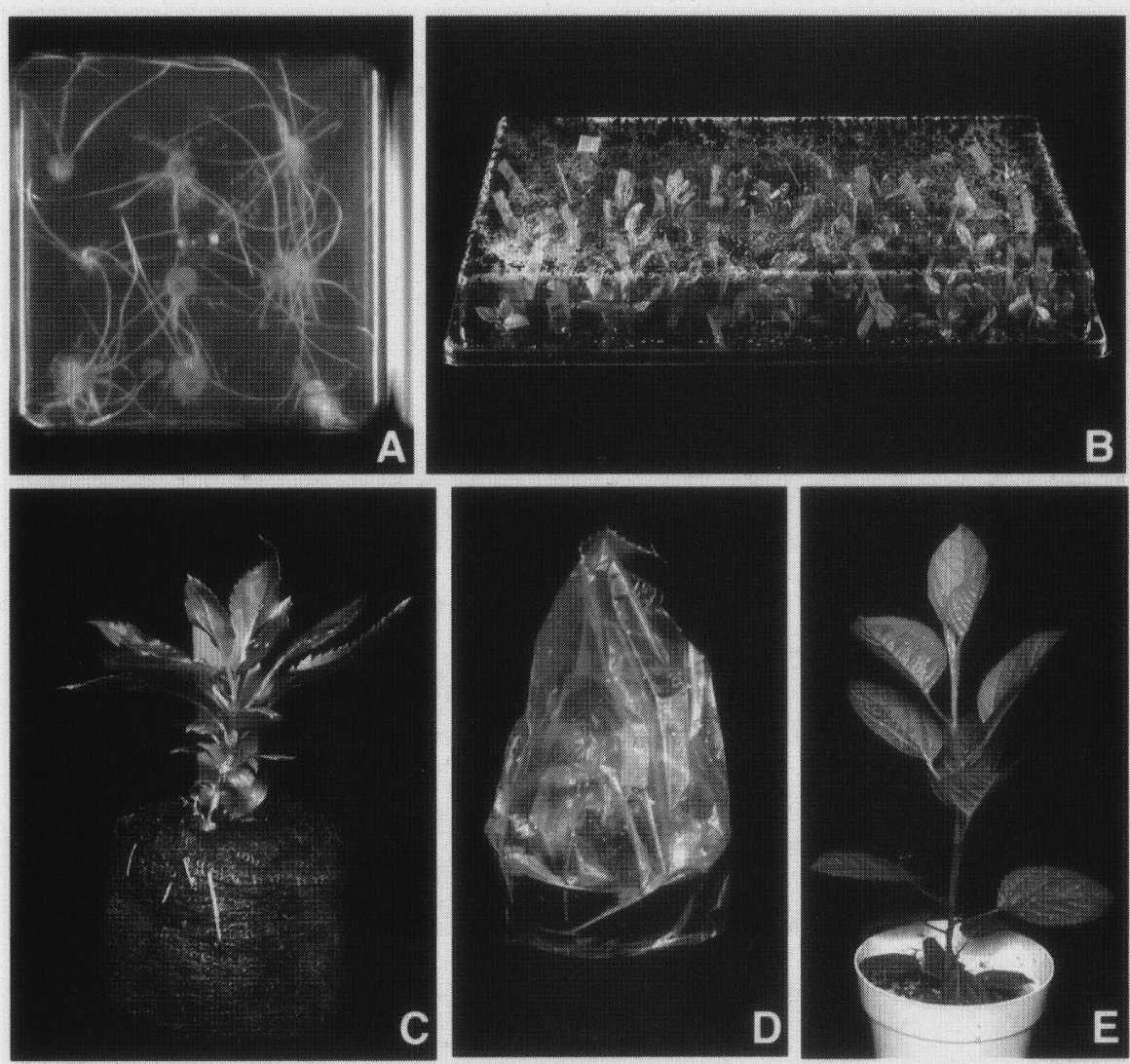

Fig. 1. Stages during rooting and acclimation of in vitro-derived apple shoots: (A) production of roots after 2 weeks in root elongation medium; (B) Jiffy-7s in humidity tray; (C) roots growing out of Jiffys; (D) acclimation in pots covered with plastic bags; $(\mathbf{E})$ established plants. III.). Prior to transfer, $10 \mathrm{~g}$ of biological plant
To root tissue-cultured plants, healthy, vigorously growing 4-week-old shoot tips (10-15 $\mathrm{mm}$ ) were transferred from proliferation medium (Bolar, 1995) into magenta boxes (V8505; Sigma, St. Louis) containing root induction medium. This medium contained Murashige and Skoog inorganic salts (Life Technologies, Grand Island, N.Y.) at half strength, supplemented with the following organic constituents: thiamine- $\mathrm{HCl}\left(1 \mathrm{mg} \cdot \mathrm{L}^{-1}\right)$, myoinositol $\left(100 \mathrm{mg} \cdot \mathrm{L}^{-1}\right)$, and IBA $\left(3 \mathrm{mg} \cdot \mathrm{L}^{-1}\right)$. Sucrose $\left(20 \mathrm{~g} \cdot \mathrm{L}^{-1}\right)$ was the carbon source and the medium was solidified with Difco-Bacto agar $\left(7 \mathrm{~g} \cdot \mathrm{L}^{-1}\right)$. The $\mathrm{pH}$ of the medium was adjusted to 5.6 with $1 \mathrm{~N} \mathrm{KOH}$. Nine to 12 shoot tips were placed vertically in each box and cultures were incubated at $25 \pm 2{ }^{\circ} \mathrm{C}$ in the dark. After 1 week, when the root apices were visible, the shoots were transferred to root elongation medium, which differed from the above root induction medium only by the omission of IBA. These cultures were incubated on racks in a growth culture room at a temperature of $25 \pm 2{ }^{\circ} \mathrm{C}$ with a 16 -h photoperiod provided by white fluorescent tubes at a photon flux of 50 to $60 \mu \mathrm{mol} \cdot \mathrm{m}^{-2} \cdot \mathrm{s}^{-1}$ for 2 to 3 weeks (Fig. 1A). In the root elongation medium the roots grew $\approx 10$ to $15 \mathrm{~mm}$.

Rooted shoots were rinsed in water to remove any medium, misted with water to prevent wilting, and then transferred to Jiffy-7 plant starter pellets (Jiffy Products, Batavia, 
protectant (Harman and Lo, 1996) (Trichoderma harzianum Rifai strain KRL-AG2, granules T-22G; BioWorks, Geneva, N.Y.) and 10 $\mathrm{g}$ of $15 \mathrm{~N}-30 \mathrm{P}-15 \mathrm{~K}$ Miracle-Gro fertilizer (Stern's Miracle-Gro Products, Port Washington, N.Y.) were mixed in a liter of water, and the Jiffy-7s were soaked in this mixture. After transfer, the Jiffy-7s were placed in trays under clear plastic humidity domes (Agway, Syracuse, N.Y.) and incubated under light in growth chambers with the same conditions as above (Fig. 1B). After 2 to 3 weeks, when roots began to grow out of the Jiffy-7s (Fig. $1 \mathrm{C})$, the plants were transferred to plastic pots (10.2-mm diameter) containing 4 peat : 1 perlite : 1 vermiculite. The pots were watered, covered with plastic bags, and placed in growth chambers at $70 \%$ to $80 \%$ relative humidity, at $22 \pm 2{ }^{\circ} \mathrm{C}$, under cool-white fluorescent tube lights (16-h photoperiod, $50-60 \mu \mathrm{mol} \cdot \mathrm{m}^{-2} \cdot \mathrm{s}^{-1}$ ) (Fig. 1D)

To acclimate the plants, after $\approx 3 \mathrm{~d}$ or when growth of a new leaf was observed, the corner of the plastic bag was cut with scissors to make a hole $\approx 1 \mathrm{~cm}$ long, and $4 \mathrm{~d}$ later the bag was removed. The pots were watered regularly and fertilized weekly with Miracle-Gro as per the manufacturer's recommendation. The plants were then maintained in the growth chamber or transferred to a greenhouse (Fig. 1E).

\section{Results and Discussion}

Zimmerman and Fordham (1985) used nonsterile peat plugs similar to the Jiffy- $7 \mathrm{~s}$ used in this research. Our previous problem of losing $40 \%$ to $50 \%$ of plants to fungal contamination in the moist Jiffy-7s was greatly reduced by the present protocol after inclusion of the biological plant protectant. Also, fertilizing (the Jiffy-7s) improved the vigor of the rooted plants. Rooting in Jiffy-7s and subsequent transfer of the Jiffy-7s into pots prevented damage to the established roots and was an effective way to handle plants at that stage. Zimmerman and Fordham (1985) acclimated plants by gradually opening the boxes over several days, and also gradually reduced the humidity in the chambers. Skirvin and Sriskandarajah (1993) suggested the use of fogging to acclimate plants. Here the use of plastic bags, and later cutting holes to acclimate the plants, was less cumbersome compared to periodically opening and closing humidity domes, allowed for independent handling of individual plants, and did not require special equipment. This technique has resulted in $70 \%$ to $100 \%$ of shoots selected in vitro producing vigorously growing, healthy plants in the greenhouse. Thus far, the cultivars Marshall McIntosh, Golden Delicious, Lib- erty, Royal Gala, and Galaxy, and M26 rootstocks have been rooted and acclimated using this protocol, with similar success rates. For some of the above cultivars, transgenic plants containing foreign genes of interest have been rooted with the same success rate. This report gives a very detailed protocol for shoot proliferation, root initiation, root elongation, acclimation, and establishment of vigorously growing plants in the greenhouse.

\section{Literature Cited}

Bolar, J.P. 1995. Examination of factors affecting the transformation of 'Marshall McIntosh' apple by Agrobacterium tumefaciens. MS Thesis, Cornell Univ., Ithaca, N.Y.

Harman, G.E. and C.T. Lo. 1996. The first registered biocontrol product for turf disease: BioTrek 22G. TurfGrass Trends 5:8-15.

Skirvin, R.M. and S. Sriskandarajah. 1993. The use of fogging and phototron units to acclimatize in vitro-derived apple shoots. HortTechnology 3:208-210.

Zimmerman, R.H. 1984. Rooting apple cultivars in vitro: Interaction among light, temperature, phloroglucinol and auxin. Plant Cell Tiss. Org. Cult. 3:301-311.

Zimmerman, R.H. and I. Fordham. 1985. Simplified method for rooting apple cultivars in vitro. J. Amer. Soc. Hort. Sci. 110:34-38. 